\title{
Gandhian Values in Health Science Education: Need for Global Revamp in Higher Education
}

\author{
Siddharth P. Dubhashi', Shashank D. Dalvi' ${ }^{2}$, RB Goel ${ }^{3}$, Nitin N. Kadam4, \\ Sudhir N. Kadam 5 , P.M. Jadhav6
}

Sci. Journal Impact

Factor: 6.1 (2018)

ICV: 90.90 (2018)

Scopus'

\begin{abstract}
Professor and Head - Department of Surgery, Associate Dean (Academics), All India Institute of Medical Sciences (AllMS), Nagpur (Former Director (Academics), IOAC Coordinator, Professor and Head, Surgery, MGMIHS, Navi Mumbai); 'Vice Chancellor, MGMIHS, Navi Mumbai; ${ }^{3}$ Registrar, MGMIHS, Navi Mumbai; ${ }^{4}$ Controller of Examinations, MGMIHS, Navi Mumbai; 5 Medical Director and Former Vice Chancellor, MGMIHS, Navi Mumbai; ${ }^{\complement}$ Vice Chairman, MGM Trust, Navi Mumbai
\end{abstract}

\section{ABSTRACT}

The $21^{\text {st }}$ century has drifted away from the Gandhian postulates, with lust for power, disrespect for religion, misuse of science and technology, unfair competition, thereby leading to ill-health. Only a healthy mind can build a healthy Nation. Our Institution strongly advocates the implementation of Gandhian values with the motto, "Wipe every tear from every eye." The paper highlights the outcome of various initiatives undertaken by the University to implement the Gandhian Values in Health Science education. The Institution Model of Integrated Curriculum aims at the holistic development of the budding health care professional, doing away with the fragmented approach to teaching-learning. We as health professionals, need to be role models for the community. The paper strongly recommends that Health Science institutions need to foster a cultural ethos, imbibing the philosophy of the Mahatma in the true sense.

Key Words: Gandhian values, Healthy mind-healthy nation, Integrated curriculum, Holistic development

\section{INTRODUCTION}

Student-centred, patient-oriented education is the need of the hour. Higher Education Institutions should recognize the importance of integrating social and cultural values into the formal curriculum. Mahatma Gandhi, a symbol of world peace, spent his entire life in the pursuit of non-violence and truth. He believed that every human being has good in him, and that no one is born evil. He advocated that it is the bond of Ahimsa and love that unites human beings. He used this as a universal method for dealing with conflicts. The $21^{\text {st }}$ century has drifted away from the Gandhian postulates, with lust for power, disrespect for religion, misuse of science and technology, unfair competition, thereby leading to ill-health. Only a healthy mind can build a healthy Nation. Gandhiji said that our body sends several signals to indicate the effects of wrong habits and lifestyles. However, modern medicine is used to mask these signals and wrongdoings.

"It is health that is real wealth and not pieces of gold and silver."
Our Institution strongly advocates the implementation of Gandhian values in all its constituent Units of Health Sciences (Medical, Nursing, Physiotherapy, Biomedical Sciences, Prosthetics, and Orthotics) The parent trust established in 1982, works with the motto, "Wipe every tear from every eye."

\section{Objectives}

1. To create an awareness regarding Gandhian philosophy amongst all stakeholders

2. To nurture a healthy work ambiance, in the light of Gandhian values

3. To foster a true sense of comradarie and team-building

4. To advocate green initiatives and a clean environment

\section{Practice}

The Institute has implemented several strategies to create awareness about Gandhian values amongst its stakeholders:

- Formulation of Vision and Mission statements in accordance with Gandhian philosophy

\section{Corresponding Author:}

Prof. Dr. Siddharth P. Dubhashi, A2/103, Shivranjan Towers, Someshwarwadi, Pashan, Pune 411008. Mobile: 9881624422; Fax: 020-25883666; Email: spdubhashi@gmail.com

ISSN: 2231-2196 (Print)

Received: 23.05 .2020
ISSN: 0975-5241 (Online)

Revised: 19.06 .2020
Accepted: 08.07 .2020
Published: 22.07 .2020 
- Display of boards in the campus, indicating Gandhian thoughts

- Paying tribute to the Father of the Nation on Republic and Independence Days, before the start of educational events like conferences, workshops

- Recitations of Vaishnav Janato

- Award of idol of Mahatma Gandhi as a token of appreciation to all guest speakers

- Khadi centre

- Exhibition on the Life of the Mahatma, on $2^{\text {nd }}$ October

- Movie depicting Gandhian values

- Use of Gandhian thoughts during formal training activities including didactic lectures

- Inclusion of Human Values and Ethics into the undergraduate and postgraduate curricula of all Health Science courses

- Tree plantation program

- Participation in Swacch Bharat Abhiyan

- Yoga sessions for a healthy mind and body

- Charity for needy patients

- Diagnostic health camps in remote villages

- Provision of financial and medical help in case of national calamities

\section{Observations}

Keeping the Gandhian values in view, various initiatives and practices have been institutionalized by the organization. The outcome of such initiatives has been analyzed:

Clean campus:

- Participation in Swacch Bharat Abhiyan

- Awards by Government of India in recognition of the same

- Participation of students, duly recognized by the Government

- Environmental protection

\section{Green initiatives}

- Tree plantation programs

- E-Governance strategies

\section{Inclusion of Gandhian values into teaching- learning process}

- Increased awareness regarding Gandhian philosophy amongst faculty and students

- Initiative taken by Faculty to include Gandhian thoughts during their lectures and mentoring sessions

- Implementation of Communication Skills module including plays depicting values of empathy and patient rights

- Initiatives taken by students to construct scripts for movies and plays depicting Gandhian values
- Overwhelming response of students for an essay writing competition organized by Indian Council of Medical Research on "Gandhi and Health"

- E-poster competition on Life of Mahatma, organized by Institution Bioethics Unit of UNESCO Chair in Bioethics

- Value-added course on Gandhian values

- Fostering freedom of thought, inquiry, creative thinking amongst students

- ReThink India awards for students who were appreciated as "scintillating students in the framework of Gandhian values"

\section{Social commitment:}

- Charity for needy patients

- Display of Gandhian thoughts at strategic places in the hospital

- Over 1000 diagnostic health camps in remote villages

- Adoption of 10 remote villages under Unnat Bharat Abhiyan

- Stoppage of open field defecation practices in villages

- Decreased mortality and morbidity from water-borne diseases as a result of Information, Education and Communication (IEC) activities in villages

- Cleanliness drives in Ashram schools and slum areas

- Grade A1 accredited Mahatma Jyotiba Phule Jan Arogya Yojana scheme of Government of Maharashtra

- Provision of financial and medical help for flood victims of State of Kerala, duly recognized by Government of Kerala

\section{Overall Development:}

- Nurturing human values in the formal education process

- Improved teacher - student and doctor - patient bonding

- Team building spirit

- Feeling of inclusiveness amongst stakeholders

- Strong inculcation of the values of social commitment, honesty, and sincerity into the minds of budding health professionals

- Self-realization, self-respect

- Patriotism

- Respect for all religions

\section{DISCUSSION}

The Institution has been striving towards quality benchmarks in higher education. In doing so, the visionary founders have always felt the need for inclusion of Gandhian Values in Health Science education. (Fig. 1). 


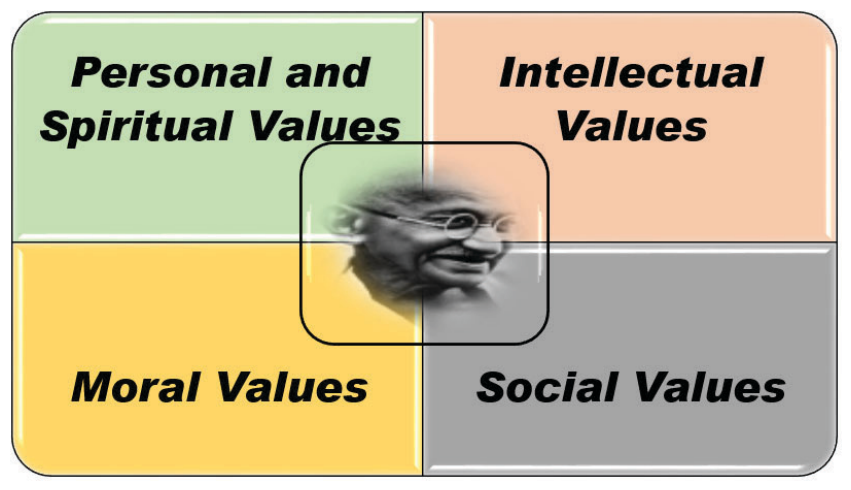

Figure 1: Gandhian values.

Spiritual values in health care are gaining immense importance. Spirituality is a universal concept in all societies and cultures and has a correlation with Quality of Life scores. Patients with the advanced disease would have a strong feeling of fulfillment of life goals. Spiritual effects are seen in a positive manner in alleviating pain ${ }^{1}$. Cultural Competence in health care is crucial. The American College of Physicians and the Association of American Medical Colleges have reiterated the value of attributes of altruism, compassion, and empathy, in dealing with patients ${ }^{2,3}$. Spiritual values provide comfort, hope, and faith in crisis ${ }^{4}$. The nursing profession is spiritual, with a deep presence, providing compassion, love, and healing 5,6 . This calls for the development of curricula on spirituality in medicine in health science Universities.

Health care professionals need to have values of integrity, trust, and a feeling of caring for others. Ethical dilemmas can pose several challenges. We need to involve patients and their families in decision-making. The individuality of every person needs to be given due respect ${ }^{7}$. The intellectual values define leadership potential in a health care professional to a great extent. The intellectual domain comprises of human, structural, and customer capitals 8 . The values of reflection, critical thinking, reasoning and judgement, open mindedness, and creativity, need to be nurtured.

The doctor-patient relationship is now moving towards a patient-provider relationship. Moral values reflect the code by which we practice 9 . Health care professionals strive towards ethical practices. In fact, ethics includes the moral values that influence one's behavior ${ }^{10}$. Moral distress in the health care profession has been described extensively with the nursing professionals, who spend a lot of time in resolving ethical dilemmas ${ }^{11}$.

The Institution Model of Integrated Curriculum aims at the holistic development of the budding health professional. This model has removed the inter-departmental barriers, thereby doing away with the fragmented approach to teaching-learning (Fig. 2).

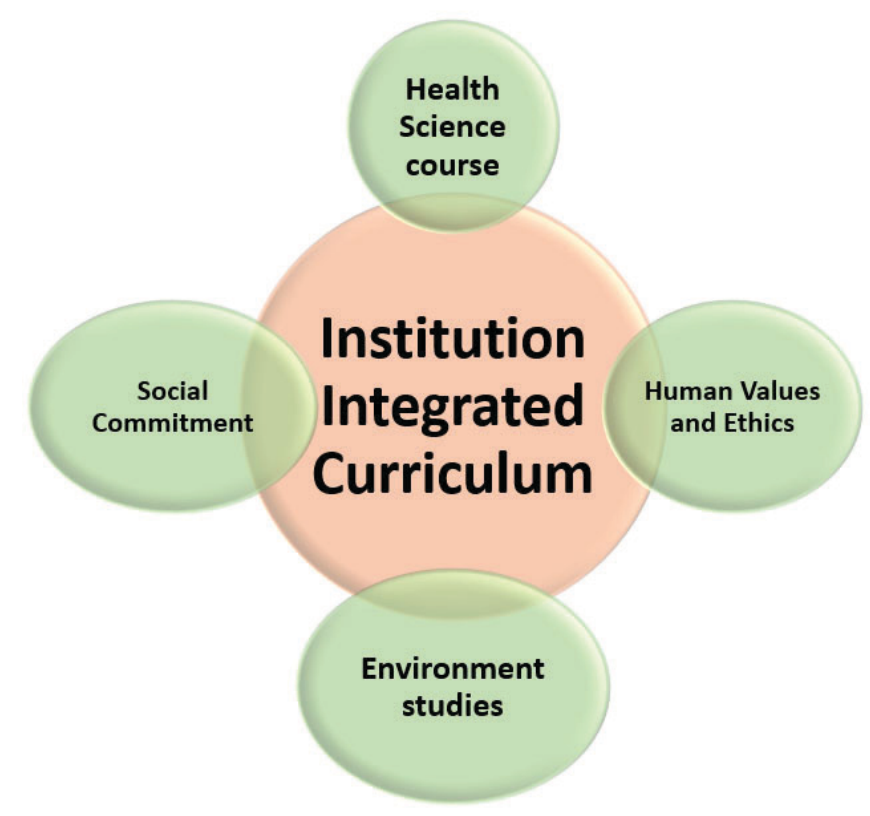

Figure 2: Institution Integrated Curriculum.

Every effort is made by the Institution to nurture the Gandhian values in a vibrant academic environment. The ethos thus created, encourages students to actively participate in various events such as the celebration of Gandhi Jayanti on $2^{\text {nd }}$ October. The film made by these students and the eyecatching exhibition on the life of the Mahatma, has been truly inspiring. In fact, such events stand testimony to the fulfillment of the Vision and Mission of the Institution. The precious teachings of the Father of the Nation are taught through several literary events like essay writing, poetry, mono acts, debates. These thematic activities are organized by the students themselves, are indeed a treat to watch. Gandhian thoughts are well depicted in all the student documents such as handbooks, log-books, and student charter.

Every guest arriving into the Institution campus first takes the blessings of the Mahatma. The statue of the Father of the Nation on the lush green campus lawns catches the eye of every visitor. The Institution has nurtured a rich tradition of felicitating the guests with our in-house woven Khadi shawl and an idol of Mahatma.

Gandhiji advocated social service and cleanliness. Tree plantation drives, adoption of villages under Unnat Bharat Abhiyan, Swachh Bharat campaign, reflect the true sense of social commitment among faculty and students. It is indeed encouraging to note the participation of alumni in many of these activities. The Swachh Bharat campaign conducted by the Institution has won accolades from the Government of India. Energy conservation measures adopted by the Institution in all its constituent Units, add to the green initiatives. Cleanliness drives are conducted periodically in the campus as well as adjacent villages. The Institution feels proud to 
note the whole-hearted voluntary participation of faculty and students in these activities.

Gandhiji knew that the future of the country was in the villages. Our Institution also believes "Village health is a sound investment". The conduct of diagnostic health camps in remote villages provides a social platform for the students to understand the importance of communication skills and important principles of bioethics including patient privacy and autonomy. The students have been proactive in conducting health awareness drives in villages, especially in relation to the stoppage of open defecation and safe sanitation practices. The dietary practices are explained to the villagers. The IEC strategies adopted by the Institution have brought about the desired changes in the community. The Institution has been at the forefront in offering required services for natural calamities and mass casualty events.

The Gandhian principle of learning by doing, is well reflected in the teaching-learning model of the Institution. The creativity of the students is brought to light by various studentcentred activities like Case-Based Learning, role plays, short projects, essay writing, and wall magazines. The Mahatma advocated the importance of understanding ones responsibility. The students, in the process of participation in all events as a team, also value this principle. It is then that they find the path for social awareness and social mindedness. The encouragement provided by the Institution for undergraduate research activities, ignites an element of critical thinking into young minds.

Recitation of Vaishnava Janato during important events of the Institution creates a serene atmosphere for teachinglearning. It is a simple endeavor to instill into the minds of all stakeholders, the definition of a Vaishnav. It is emphasized to the students that it is essential to understand the agony of their patients that they should refrain from speaking lies, have true respect for others, and have the best of knowledge without an element of ego. This gesture adds flavor to the rich cultural framework of the Institution.

The Father of the Nation always maintained that students should refrain from politics. Students should never exploit the autonomy that is imparted to them by the education system. They need to be well informed regarding the evils of society which can ruin their professional ambitions. The Institution has adopted a student-centric nomination system for appointment of student representatives on various bodies. In fact, utmost care is taken to maintain adequate gender representation as well. The standard operating procedures of the Institution ensure adequate student autonomy in decision-making. The well-drafted Student Charter outlines the roles and responsibilities of the Student and the Institution towards each other.

The Institution has taken an initiative to start the Bioethics
Unit in collaboration with the UNESCO Chair in Bioethics. The Unit exhibits active participation in accordance with the World Bioethics Day theme and undertakes short research projects. The Boards of Studies (Pre-Clinical, Para-Clinical, Medicine and Allied, Surgery and Allied, Super-Specialty, Nursing, Physiotherapy, and Biomedical Sciences, have identified various sub-topics related to Bioethics in their respective specialties for Undergraduate and Postgraduate programs. Bioethics forms an integral part of the induction programs for the undergraduate and postgraduate students. Professionalism, Communication skills, doctor-patient relationship, research ethics, environmental ethics, are some of the key features of the training program. The Unit has pioneered the tradition of administering a pledge to all members of the Bioethics Student Wing.

The Bioethics Unit conducts structured training sessions for Human Values and Ethics, for all health science students. It is noteworthy to note the positive response of students for these sessions. Moreover, the faculties are self-motivated to conduct these sessions. In fact, periodic training programs on Bioethics are also conducted for faculty. The Doctor-Patient relationship and Professionalism are depicted in these training sessions with the use of videos and role-plays. This makes the teaching-learning process more enjoyable and increases the receptiveness of students to these values. The success of these activities lies in a remarkable change in the attitude and behavior of several stakeholders. Moreover, the students who benefit from these sessions act as mentors for their junior colleagues, thereby facilitating Peer-Assisted Learning.

The learning resource centre is a temple in any Higher Education Institution. We have strived to build up a unique collection of Gandhian literature for the benefit of our students and faculty. These documents provide a deep insight into the philosophy rooted behind the Gandhian values. This has triggered off a unique initiative of formulating value-added courses related to Gandhian Values.

The Khadi Centre of the Institution has lots to offer in the present education system Students are made aware of the importance of Khadi, which is much more than just a cloth. The message behind the hand spun and hand-woven cotton fabric needs to be driven strongly into the young minds. Khadi reflects national integrity, self-sufficiency, and morality. In fact, the University Grants Commission (UGC) in India has already advocated the use of Khadi in all convocation ceremonies and other special occasions of Higher Education Institutions in the country. It is indeed a matter of pride for our Institution to have adopted this strategy way back since inception.

Gandhiji has advocated the importance of exercise for the healthy mind. Unhealthy lifestyles have been the root cause of disharmony. The Institution has always stressed upon the 
importance of Yoga for its stakeholders. The foundation of Yoga therapy has been related to Ahimsa ${ }^{12}$. We strictly prohibit the use of liquor in campus and advocate a clean healthy vegetarian diet for all. The Institution endeavors to help students to practice self-restraint with regards to harmful addictions. It needs to be instilled into the minds of students, that the rich Indian traditions and culture are now being adopted globally.

The Institution has always strived to bring out the importance of the holistic approach to teachinglearning. Integrated teaching is the solution for better outcome of graduate attributes in health sciences. An integrated curriculum as "education that is organized in such a way that it cuts across subject matter lines, bringing together various aspects of the curriculum into meaningful association to focus upon broad areas of study." 13 Institutions are shifting from traditional discipline-based curricula to the SPICES Model: student-centered learning, problem-based learning, integrated teaching, community-based education, elective programs, and a systemic approach ${ }^{14}$. The Institution convened a landmark meeting of eminent academicians in 2018 to deliberate upon quality benchmarks in higher education. The event emphasized the role of integrated teaching and the hidden curriculum in health science education. The integrated teaching model provides an opportunity for holistic learning. Interdisciplinary interactions pave the way for effective and meaningful research, which can be easily translated into practice for effective patient care.

The disciplines of Ayurveda and other alternative systems can no longer be ignored. The Wellness Centre of our Institution caters to a variety of chronic illnesses as well as provides relaxation therapy, a stress buster for health care professionals. Quality of Life issues is gaining importance for every disease. The treatment protocol no longer ends with the patient feeling better or asymptomatic, but cares for the rehabilitation of the patient. The Institution has facilities not only for psychological counseling but also for prosthetic and orthotic requirements. This helps to inculcate a spirit of a holistic approach to health care. The teaching hospitals provide the best of facilities at subsidized costs and even free of charge for needy patients.

The Mahatma clearly put forth the seven deadly sins that would destroy the society: Wealth without work; pleasure without conscience; knowledge without character; commerce without morality; science without humanity; worship without sacrifice; politics without principle ${ }^{15}$. Hatred and violence is now an integral part of the society. The technology of today, may be the error of tomorrow. The hanging sword of Bioterrorism has created panic waves across the globe.
What are we heading for? This is the time that the Higher Education Institutions revisit their curricula and firmly imbibe the Gandhian values. The Gandhian model of teachinglearning needs to be discussed at length on a global platform.

\section{Recommendations}

1. Every Higher Education Institution in the country should adopt the Gandhian values into its Curriculum.

2. The Learning Resource Centre at every HEI should have a dedicated section for Gandhian literature.

3. Gandhian thoughts should form an integral component of every induction program.

4. Institutions should conduct an annual Oration, inviting reputed speakers to elaborate upon any facet of the life of the Mahatma.

5. It is worthwhile to explore the possibility of observing a 'Khadi Day' in the Institution.

6. Doctoral Programs in Bioethics are the need of the hour. Appropriate incentives should be provided to faculty pursuing such programs.

7. Every Health Science Institution should include undergraduate students as part of the village adoption program.

8. The best practices of any Institution should clearly reflect the adoption of any of the Gandhian values in the Institution culture. This should be given due importance in the accreditation of the institution.

\section{CONCLUSION}

Inclusion of Gandhian values into Health Science education has proved to be an excellent initiative of our Institution. We as health professionals, need to be role models for the community, with moral, and ethical values in the true sense. The technological advancements should be coupled with the much need human touch for optimum outcome in healthcare. The health science graduate should be able to implement the blend of moral, spiritual, social, and intellectual values in society for an optimal outcome. Implementation of Gandhian values into the health science curriculum will foster a rich cultural ethos in a rich academic environment, thereby nurturing good citizens.

Acknowledgement: Authors acknowledge the immense help received from the scholars whose articles are cited and included in references of this manuscript. The authors are also grateful to authors / editors / publishers of all those articles, journals and books from where the literature for this article has been reviewed and discussed.

\section{Source of funding: NIL}

The said manuscript has not been presented in any meeting.

\section{Conflict of interest: NIL}




\section{REFERENCES}

1. Puchalski CM. The role of spirituality in health care. Proc (Bayl Univ Med Cent) 2001;14(1):352-357.

2. Lo B, Quill T, Tulsky T, for the ACP-ASIM End-of-Life Care Consensus Panel Discussing palliative care with patients. Ann Intern Med. 1999;130:744-749.

3. Association of American Medical Colleges. Report I: Learning Objectives for Medical Student Education: Guidelines for Medical Schools. Medical School Objectives Project. Washington, DC: American Association of Medical Colleges; 1998:4. Available at http://www.aamc.org/meded/msop/report1.htm (accessed March 2020).

4. Jackson C. Healing ourselves, healing others. Holistic Nursing Practice 2004;18:127 -141.

5. Goddard NC. A response to Dawson's critical analysis of 'spirituality as integrative energy'. Journal of Advanced Nursing 2000;31:968 -979.

6. Carroll B. A phenomenological exploration of the nature of spirituality and spiritual care. Mortality 2001;6:81-98.

7. Benator S, Upshur R. Virtues and values in medicine revisited: individual and global health. Clinical Medicine 2014;14(5):495499.
8. Alshawabkeh RKE. The impact of intellectual capital development on provided health services quality. International Journal of Advanced Educational Research 2018;3(2):481-486.

9. Timimi FK. Medicine, morality and health care social media. BMC Medicine 2012;10:83.

10. Evans JM. The changing ethics of health care. Caring for the Ages 2016;17(7):12.

11. Raines ML. Ethical decision making in nurses Relationships among moral reasoning coping style, and ethics stress. JONA's Healthcare Law Ethics and Regulation 2000;2(1):29-41.

12. Bhargav H. The principles and practice of Yoga in health care Int J Yoga 2018;11(1):86-87.

13. Shoemaker BJE. Integrative Education: A Curriculum for the Twenty-First Century. OSSC Bulletin 1989;33(2):n2.

14. Harden RM, Sowden S, Dunn WR. Educational strategies in curriculum development: the SPICES model. Med Educ 1984;18(4):284-297.

15. Dundar H, Erdogan E, Hareket E. A role model in light of values: Mahatma Gandhi. Educational Research and Reviews 2016;11(20):1889-1895. 